\title{
STRATEGI PENGEMBANGAN AKTIVITAS WISATA \\ DI OBJEK WISATA IKAN SAKTI SUNGAI JANIAH KABUPATEN AGAM
}

\author{
Randi Hidayat $^{1}$, Yuliana ${ }^{2}$, Hijriyantomi Suyuthie ${ }^{2}$ \\ Program Studi D4 Manajemen Perhotelan \\ Jurusan Pariwisata \\ FPP Universitas Negeri Padang \\ randihidayat411@gmail.com
}

\begin{abstract}
This research aims to formulate a development strategy that consists of strengths, weaknesses, opportunities and threats of tourism activities in the tourism object Ikan Sakti Sungai Janiah. This research is a descriptive research with qualitative data. Data collection techniques in this research were conducted by using the method of interviewing, observation and documentation involving several informants by using purposive sampling technique. The results of this study indicate that: 1) The strength of the development of tourism activities in the tourism object Ikan Sakti Sungai Janiah is the existence of a supportive land, there has been a conscious group of tourism, beautiful atmosphere and uniqueness of tourist attractions and traditions that are not owned by other regions. 2) The weakness of the development of tourism activities in the tourism object Ikan Sakti Sungai Janiah is the land that still belongs to the community, not regular art and cultural events, the security of tourists wich are not guaranteed and the lack of capital and community skills. 3) Opportunities from the development of tourism activities in the tourism object Ikan Sakti Sungai Janiah is the availability of new employment opportunities for the community, adding tourist attractions supporting facilities, the cooperation between various agencies, and the emergence of groups that support tourism activities. 4) The threat of tourism activity in the tourism object Ikan Sakti Sungai Janiah is the increasing of waste, the destruction of the environment, the emergence of groups that disturb the security of tourists, and illegal traders. Strategy of development of tourism activity in the tourism object Ikan Sakti Sungai Janiah is a) to maximize the surrounding potential of land and human resources, b) cooperate with various institutions and community, c) optimize the participation of various circles related to tourism activities, $d$ ) adding supporting facilities for the smoothness of tourism activities.
\end{abstract}

Keywords: Strategy, Development, Tourist Activities.

\section{PENDAHULUAN}

Provinsi Sumatera Barat merupakan salah satu provinsi yang serius dalam mengembangkan sektor pariwisata di daerah. Hal ini tergambar pada Visi Pembangunan Pariwisata, Seni dan Budaya Sumatera Barat periode 2006-2020, yaitu "Terwujudnya
Sumatera Barat sebagai destinasi utama daerah Indonesia bagian barat dengan daya saing global dan berwawasan lingkungan dengan ciri lokal adat, agama, alam dan budaya". Demi terwujudnya visi tersebut, dikembangkanlah Misi Pariwisata yaitu "Menyelenggarakan pembangunan 
pariwisata, seni dan budaya di Kabupaten/Kota dengan pendekatan adat, budaya dan agama demi pencerahan budaya daerah dan peningkatan kesejahteraan masyarakat. Mengembangkan produk wisata yang berwawasan lingkungan, bertumpu pada budaya daerah, peninggalan budaya dan pesona alam lokal yang bernilai tambah tinggi dan berdaya saing global. Meningkatkan peran serta masyarakat dalam pengembangan kepariwisataan. Menjadikan pariwisata, seni dan budaya sebagai lokomotif pemberdayaan ekonomi rakyat". Atas potensi wisata yang sangat besar tersebut, membuat Sumatera Barat menjadi salah satu tujuan destinasi wisata favorit di Indonesia dan menjadi salah satu dari 13 gerbang masuk utama pariwisata ke Indonesia.

Sebuah destinasi wisata harus memiliki aktivitas wisata yang dapat dilakukan oleh wisatawan. Menurut Hadinoto dalam Angguni (2016), "aktivitas wisata adalah apa yang dikerjakan wisatawan, atau apa yang menjadi motivasi wisatawan untuk datang ke destinasi, yaitu keberadaan mereka dalam waktu setengah hari sampai berminggu-minggu". Adapun beberapa aktivitas wisata yang dapat dilakukan oleh wisatawan antara lain melihat pemandangan alam, hiking, berakit/bersampan, bersepeda, camping, berlayar, menyelam, panjat tebing, photography, melihat seni dan budaya lokal, mengunjungi taman rekreasi, berbelanja souvenir, photography dll. Menurut Inskeep dalam Ingkadijaya
(2016: 40), aktivitas wisata dapat dibagi kedalam tiga kelompok, yaitu aktivitas wisata alam, aktivitas wisata budaya dan aktivitas wisata khusus.

Aktivitas wisata yang ada di objek wisata Ikan Sakti Sungai Janiah saat ini masih sangat terbatas. Perlu diadakan pengembangan aktivitas wisata lain karena memiliki potensi dan daya dukung untuk dikembangkan. Berdasarkan analisis strategi pengembangan yang dilakukan, diharapkan dapat menarik minat dan jumlah wisatawan untuk berkunjung.

Berdasarkan observasi awal yang peneliti lakukan pada tanggal 26 Maret 2017, aktivitas wisata yang dapat dilakukan wisatawan hanyalah sekedar melihat dan memberi makan ikan serta melihat pemandangan di atas Bukik Batanjua. Belum ada pengembangan aktivitas lainnya yang menarik dan dapat membuat wisatawan untuk betah berada lama di objek wisata Ikan Sakti Sungai Janiah Kabupaten Agam. Pada saat peneliti melakukan wawancara pra penelitian dengan 10 orang wisatawan, semua wisatawan tersebut menyatakan masih terbatasnya aktivitas wisata yang dapat mereka lakukan. Para wisatawan menyatakan bahwa aktivitas wisata yang mereka lakukan saat ini di objek wisata Ikan Sakti Sungai Janiah terasa membosankan. Sehingga wisatawan tersebut belum tertarik untuk datang kembali ke objek wisata Ikan Sakti Sungai Janiah.

Luasnya lahan potensial yang ada di objek wisata Ikan Sakti Sungai Janiah Kabupaten Agam, juga belum 
dimanfaatkan secara optimal oleh pengelola objek wisata. Masih banyak area yang ditumbuhi oleh rumput liar dan lahan hijau yang belum dimanfaatkan potensinya. Jalur menuju puncak Bukik Batanjua sudah dilengkapi dengan anak tangga yang dibuat dari dasar hingga bahu bukit, namun saat ini tangga tersebut kurang terawat. Di puncak bukit Batanjua aktivitas wisata yang dilakukan wisatawan hanyalah sekedar melihat pemandangan alam dan berfoto dengan kamera atau handphone yang mereka bawa.

Aktivitas wisata budaya seperti tradisi pengafanan dan penguburan ikan yang mati belum menjadi sebuah tontonan yang menarik bagi wisatawan. Padahal tradisi ini telah ada sejak dahulu dan dilakukan secara turun temurun. Penampilan seni anak daerah seperti randai, permainan alat musik dan tari daerah juga sudah jarang dilakukan di objek wisata ini.

Permasalahan dalam hal aktivitas wisata khusus yang penulis temui adalah belum ada aktivitas berbelanja wisatawan seperti souvenir shop. Fasilitas berbelanja yang tersedia baru sebatas warung-warung kecil yang menjual makanan ringan. Untuk souvenir di objek wisata Ikan Sakti Sungai Janiah baru tersedia baju kaos yang bergambar ikan sakti. Namun pada saat ini souvenir baju kaos ini terhenti dan tidak ada lagi yang menjual karena kurangnya minat wisatawan.

Berdasarkan hal tersebut, maka penelitian ini bertujuan untuk menentukan strategi pengembangan (strengths, weaknesses, opportunities dan threats) aktivitas wisata di objek wisata Ikan Sakti Sungai Janiah Kabupaten Agam yang ditinjau dari aktivitas wisata alam, aktivitas wisata budaya dan aktivitas wisata khusus.

\section{METODOLOGI PENELITIAN}

Jenis penelitian ini adalah penelitian deskriptif dengan data kualitatif. Teknik pengumpulan data dilakukan dengan cara metode observasi, wawancara dan dokumentasi. Informan penelitian ini adalah 2 orang pegawai DISPARPORA Kabupaten Agam, 1 Orang pengelola objek wisata, 3 orang masyarakat dan 4 orang wisatawan. Jenis data yang digunakan adalah data primer dan data sekunder.Instrumen dalam penelitian ini adalah peneliti itu sendiri.Teknik analisis data dalam penelitian ini adalah reduksi data, penyajian data dan penarikan kesimpulan.

\section{HASIL DAN PEMBAHASAN}

\section{Hasil Penelitian}

Aktivitas wisata merupakan salah satu elemen penting yang harus ada di sebuah objek wisata. Adanya aktivitas wisata yang disediakan, dapat menjadi salah satu motivasi dan alasan bagi wisatawan untuk berkunjung ke objek wisata tersebut. Adapun kelompok aktivitas wisata yang dapat dilakukan oleh wisatawan antara lain aktivitas wisata alam, aktivitas wisata budaya dan aktivitas wisata khusus. Aktivitas wisata alam yang 
ada di objek wisata Ikan Sakti Sungai Janiah saat ini antara lain melihat pemandangan alam dan mendaki bukit. Sedangkan untuk aktivitas wisata budaya antara lain randai dan penguburan ikan yang mati. Untuk aktivitas wisata khusus adanya souvenir yang dijual namun belum dikembangkan secara spesifik di objek wisata Ikan Sakti Sungai Janiah.

Berdasarkan penelitian yang telah dilakukan, maka didapatkan hasil penelitian sebagai berikut:

a. Kekuatan dari pengembangan aktivitas wisata di objek wisata Ikan Sakti Sungai Janiahantara lain: (1) Adanya potensi lahan dan daerah di objek wisata yang dapat dikembangkan untuk aktivitas wisata. (2) Telah ada kelompok sadar wisata, (3) Suasana objek wisata yang masih asri dan keunikan dari Bukik Batanjua, (4) Memiliki banyak potensi aktivitas wisata yang dapat dikembangkan,

Memiliki tradisi yang tidak ada di daerah lain.

b. Kelemahan dari pengembangan aktivitas wisata di objek wisata Ikan Sakti Sungai Janiah antara lain: (1) Sebagian lahan masih menjadi hak milik masyarakat. (2) Acara seni dan budaya belum diadakan secara rutin oleh pengelola. (3) Keamanan wisatawan masih belum terjamin. (4) Kurangnya modal dan kemampuan masyarakat dalam mengelola sumber daya dan teknologi.

c. Peluang dari pengembangan aktivitas wisata di objek wisata Ikan Sakti Sungai Janiah antara lain: (1) Membuka lapangan pekerjaan baru bagi masyarakat setempat. (2) Meningkatan minat dan kunjungan wisatawan. (3) Penambahan fasilitas penunjang aktivitas wisata. (4) Adanya kerja sama antara pemerintah, pengelola dan masyarakat untuk pengembangan aktivitas wisata. (5) Adanya pelatihan keterampilan dan teknologi penunjang aktivitas wisata. (6) Adanya kelompok/ komunitas yang mendukung aktivitas wisata yang dikembangkan.

d. Ancaman dari pengembangan aktivitas wisata di objek wisata Ikan Sakti Sungai Janiah antara lain: (1) Intensitas sampah meningkat karena pedagang dan wisatawan yang membuang sampah sembarangan. (2) Rusaknya 
keasrian lingkungan.

Timbulnya kelompok kelompok yang mengganggu ketertiban objek wisata seperti pemalakan dan pedagang liar. (4) Adanya jenis usaha yang berdiri tanpa ada izin resmi. (5) Pengaruh budaya luar yang tidak sesuai dengan lingkungan sekitar objek wisata.

e. Strategi pengembangan aktivitas wisata di objek wisata Ikan Sakti Sungai Janiah adalah sebagai berikut:

1) Potensi sumber daya alam yang telah dimiliki objek wisata Ikan Sakti Sungai Janiah dapat dimanfaatkan untuk mengembangkan

berbagai macam aktivitas wisata seperti hiking, bersampan, panjat tebing, melihat seni dan budaya lokal, berbelanja di souvenir shop dan photography.

2) Pemerintah bersama dengan pengelola dapat melakukan penambahan fasilitas - fasilitas penunjang untuk pengembangan aktivitas wisata alam, aktivitas wisata budaya dan aktivitas wisata khusus yang dikembangkan.

3) DISPARPORA

Kabupaten Agam dapat mengadakan kerja sama dengan dinas - dinas lain seperti Dinas Sosial, dan Dinas Komunikasi dan Informatika untuk melakukan pelatihan terhadap masyarakat, khususnya kelompok sadar wisata yang ada di objek wisata Ikan Sakti Sungai Janiah dalam bidang keterampilan

(manajemen wisata, keterampilan membuat souvenir, alat - alat dan fasilitas penunjang aktivitas wisata) dan teknologi pendukung wisata (Internet, komputer, mesin counter dll).

4) Melakukan kerja sama dengan komunitas komunitas yang berkaitan dengan aktivitas wisata yang dikembangkan agar dapat melakukan edukasi mengenai aktivitas wisata tersebut.

5) DISPARPORA

Kabupaten Agam dapat melakukan pelatihan 
untuk operator maupun

guide dari masyarakat

setempat

untuk

memenuhi kebutuhan

informasi dan

kebutuhan wisatawan

selama berada di objek

wisata Ikan Sakti

Sungai Janiah

Kabupaten Agam.

6) Pihak pengelola dapat melakukan kerja sama dengan

Dinas

Kebersihan Kabupaten

Agam untuk

penyediaan fasilitas -

fasilitas kebersihan

guna menunjang

kebersihan dan

keindahan di objek wisata.

7) Mengoptimalkan peran serta pengelola dan masyarakat sekitar objek wisata untuk menghindari

kemungkinan hal - hal yang mengganggu ketertiban dan keamanan objek wisata Ikan Sakti Sungai Janiah.

8) Menerapkan peraturan - peraturan yang mengikat untuk usaha usaha yang akan didirikan disekitar objek wisata Ikan Sakti Sungai Janiah agar tidak terjadi persaingan yang tinggi.

9) Mengadakan musyawarah dengan masyarakat pemilik lahan untuk pengembangan aktivitas wisata yang memerlukan lahan yang luas. Hal ini untuk mencari kesepakatan mengenai hak tanah yang akan di pakai.

10) Mengadakan promosi untuk kegiatan seni dan budaya (randai, saluang, pertunjukan musik tradisonal dan penguburan ikan) yang rutin dilakukan setiap waktu untuk menarik minat dan jumlah kunjungan wisatawan ke objek wisata Ikan Sakti Sungai Janiah.

11) Mengoptimalkan peran kelompok sadar wisata untuk bersama - sama menjamin keamanan dan keselamatan wisatawan selama melakukan aktivitas wisata di objek wisata Ikan Sakti Sungai Janiah.

12) Melakukan kerja sama dengan Dinas

Perindustrian dan Perdagangan Koperasi Usaha Kecil dan 
Menengah dalam hal pemberian modal kepada pengelola dan masyarakat untuk mengembangkan usaha seperti souvenir shop, jasa photography dan aktivitas wisata di objek wisata Ikan Sakti Sungai Janiah.

13) Mendirikan posko keamanan dan pengawasan di sekitar objek wisata untuk menjamin kenyamanan, ketertiban dan keamanan aktivitas wisata.

\section{Pembahasan}

\section{a. Aktivitas Wisata Alam}

Menurut Inskeep dalam Ingkadijaya (2016), "aktivitas wisata alam adalah aktivitas yang dilakukan wisatawan di area wisata alam". Aktivitasaktivitas tersebut diantaranya adalah menikmati pemandangan alam, bermain dialam terbuka, mendaki gunung, berkemah, arung jeram, berwisata dipantai, snorkeling, scuba diving, memancing, mandi air panas, eksplorasi gua, mengunjungi kebun binatang atau taman safari, mengunjungi kebun raya dan mengunjungi area pertanian.

Berdasarkan hasil penelitian, objek wisata Ikan Sakti Sungai Janiah berpotensi untuk dikembangkan berbagai macam aktivitas wisata alam. Hal ini didukung oleh lokasi objek wisata yang berada di wilayah perbukitan dan masih asri. Saat ini, aktivitas wisata alam yang ada di objek wisata ini adalah hanya sebatas melihat dan memberi makan ikan. Berdasarkan potensi yang dimiliki, pengembangan aktivitas wisata lain yang dapat dilakukan adalah jalan kaki (hiking), bersampan dan panjat tebing.

b. Aktivitas Wisata Budaya Menurut Inskeep dalam Ingkadijaya (2016), "Aktivitas wisata budaya adalah aktivitas wisatawan menikmati atraksi wisata budaya". Aktivitas-aktivitas wisata tersebut diantaranya adalah mengunjungi situs budaya, sejarah dan arkeolagi, melihat seni dan budaya lokal seperti adat istiadat, upacara adat dan pakaian tradisional, melihat aktivitas ekonomi yang menarik seperti pengolahan teh, pengolahan karet, dan 
teknik bercocok tanam tradisional, melihat arsitektur bangunan rumah, gereja, masjid, dan bangunan-bangunan

lainnya, mengunjungi museum, menonton festival budaya.

Objek wisata Ikan Sakti Sungai Janiah belum memiliki aktivitas wisata budaya yang rutin dilakukan setiap waktu. Aktivitas wisata budaya yang pernah dilakukan di objek wisata ini adalah randai, pertunjukan seni musik tradisional dan penguburan ikan yang mati. Pengembangan aktivitas wisata budaya dalam hai ini adalah melihat seni dan budaya lokal perlu dilakukan pengembangan agar aktivitas wisata budaya ini dapat terus berjalan dan menjadi daya tarik untuk wisatawan berkunjung ke objek wisata Ikan Sakti Sungai Janiah.

\section{c. Aktivitas Wisata Khusus}

Menurut Inskeep
dalam Ingkadijaya (2016),
"Aktivitas wisata khusus
adalah aktivitas wisatawan
menikmati / memanfaatkan
atraksi wisata yang memang
sengaja dibuat untuk
memenuhi kebutuhan
rekreasi penduduk lokal dan

wisatawan". Aktivitasaktivitas tersebut diantaranya adalah mengunjungi taman rekreasi, berbelanja dipusatpusat perbelanjaan / souvenir shop, photography dan menonton kompetisi olahraga.

\begin{tabular}{|c|c|}
\hline \multicolumn{2}{|l|}{ Aktivitas } \\
\hline ainnya & \\
\hline kembangkan & $\pi$ \\
\hline a Ikan Sakti & \\
\hline adalah & kh \\
\hline
\end{tabular}

Pengembangan yang dapat dilakukan adalah berbelanja di souvenir shop dan photography. Kedua aktivitas wisata khusus ini berpotensi untuk dikembangkan di objek wisata Ikan Sakti Sungai Janiah karena memiliki daya dukung untuk aktivitas tersebut.

\section{SIMPULAN DAN SARAN}

\section{Simpulan}

Berdasarkan

hasil penelitian dan pembahasan diatas, maka dapat disimpulkan bahwa:

a. Objek wisata Ikan Sakti Sungai Janiah Kabupaten Agam memiliki potensi yang besar untuk dilakukan pengembangan aktivitas wisata. Namun, hal ini belum mendapat perhatian 
penuh dari berbagai pihak seperti pemerintah, pihak pengelola dan masyarakat. Terlihat dari masih sangat terbatasnya aktivitas wisata alam, aktivitas wisata budaya dan aktivitas wisata khusus yang dapat dilakukan oleh wisatawan di objek wisata Ikan Sakti Sungai Janiah.

b. Berdasarkan analisis SWOT yang telah dilakukan, maka dapat ditemukan kekuatan dan peluang untuk pengembangan aktivitas wisata di objek wisata Ikan Sakti Sungai Janiah. Namun, juga ditemukan kelemahan dan ancaman yang dapat mengganggu pengembangan yang dilakukan. Untuk itu, digunakan matriks SWOT untuk dapat merumuskan strategi pengembangan aktivitas wisata di objek wisata Ikan Sakti Sungai Janiah yang dapat memaksimalkan kekuatan dan peluang serta meminimalisir kelemahan dan ancaman yang ada.

2. Saran
a. Bagi
DISPARPORA

Kabupaten Agam agar dapat merealisasikan strategi pengembangan aktivitas wisata di objek wisata Ikan Sakti Sungai Janiah terutama untuk aktivitas wisata alam, aktivitas wisata budaya dan aktivitas wisata khusus agar berdampak pada kepuasan wisatawan berkunjung ke objek wisata. Selain itu diharapkan adanya kerja sama dari dinas lain untuk peningkatan fasilitas dan sumber daya manusia di sekitar objek wisata Ikan Sakti Sungai Janiah

b. Bagi pengelola objek wisata Ikan Sakti Sungai Janiah agar lebih memperhatikan kondisi objek wisata dan dapat mengembangkannya ke arah yang lebih baik.

c. Bagi Masyarakat sekitar objek wisata Ikan Sakti Sungai Janiah diharapkan dapat berpartisipasi aktif dalam mengelola dan mengembangkan objek wisata dan selalu meningkatkan kemampuan diri seperti keterampilan dan kreatifitas diri berdasarkan sumber daya yang ada disekitar objek wisata.

d. Bagi Fakultas Pariwisata dan Perhotelan Universitas Negeri Padang agar dapat mengadakan penyuluhan dan pelatihan tentang peningkatan sumber daya manusia dan pentingnya 
aktivitas wisata di sebuah objek wisata

\section{DAFTAR PUSTAKA}

Angguni, Frisye. 2016. Strategic

Planning Aktivitas Wisata di

Panorama Bukik Siduali Tabek

Patah. Padang: Universitas

Negeri Padang.

Ingkadijaya, Rahmad dkk. 2016.

Aktivitas Wisata Pilihan Keluarga

Perkotaan. Jakarta: Jurnal

Khasanah Ilmu Volume 7 No. 1.

(Diunduh pada 30/01/2018)

Maryam,Silvia. 2011. Pendekatan

SWOT Dalam Pengembangan

Objek Wisata Kampoeng Djowo

Sekatul Kabupaten Kendal.

Semarang: Universitas

Diponegoro.

Utama dan Mahadewi. 2012. Metode Penelitian Pariwisata \&

Perhotelan. Yogyakarta: Andi

Visi Pembangunan Pariwisata, Seni dan Budaya Sumatera Barat periode 2006-2020 (Diunduh pada $30 / 01 / 2018$ ) 